\title{
A Nationwide Survey on the Facilities and Personnel for Endoscopic Sedation: Results from 50 Qualified Endoscopy Units of Teaching Hospitals Accredited by the Korean Society of Gastrointestinal Endoscopy (KSGE)
}

\author{
Seon-Young Park ${ }^{1 *}$, Jun Kyu Lee ${ }^{2^{*}}$, Jung-Wook Kim ${ }^{3}$, Tae Hee Lee ${ }^{4}$, Chang-Hwan Park', Jae-Yong Jang ${ }^{3}$, Byung-Wook Kim ${ }^{5}$, Byung \\ Ik Jang ${ }^{6}$, the Quality management and Endoscopic sedation committee of Korean Society of Gastrointestinal Endoscopy (KSGE) \\ ${ }^{1}$ Department of Internal Medicine, Chonnam National University Medical School, Gwangju, ${ }^{2}$ Department of Internal Medicine, Dongguk \\ University Ilsan Hospital, Goyang, ${ }^{3}$ Department of Internal Medicine, Kyung Hee University College of Medicine, Seoul, ${ }^{4}$ Institute for \\ Digestive Research, Soonchunhyang University Seoul Hospital, Seoul, ${ }^{5}$ Department of Internal Medicine, Incheon St. Mary's Hospital, \\ College of Medicine, The Catholic University of Korea, Incheon, ${ }^{6}$ Department of Internal Medicine, Yeungnam University College of \\ Medicine, Daegu, Korea
}

Background/Aims: This study aimed to determine the current status of facilities, equipment, and personnel for endoscopic sedation from endoscopy units of representative hospitals in South Korea.

Methods: A questionnaire survey was conducted on 50 qualified endoscopy units accredited by the Korean Society of Gastrointestinal Endoscopy.

Results: All included endoscopy units had regulations and educational programs regarding sedation training for endoscopists and nursing personnel. There present one assisting nurse during endoscopy in 35 units (70\%) and at least two nurses in 12 units (24.0\%). All endoscopy units had examination rooms equipped with oxygen supply and suction systems. Endoscopist-directed sedation was performed in 48 units (96.0\%). Propofol-based sedation was the most used sedation method. All units had a separate recovery bay. The daily number of patients per bed was greater than 10 in 17 units (34.0\%). In $26(52.0 \%)$ units, a single nurse cared for $\geq 10$ patients per day. All the units fulfilled the discharge criteria.

Conclusions: This study presents data regarding endoscopic sedation clinical practice in 50 endoscopy units in South Korea. This study presents the current status of endoscopic sedation clinical practice in 50 qualified endoscopy units accredited by the KSGE, which provide excellent quality management. Clin Endosc 2021;54:843-850

Key Words: Facility; Gastrointestinal endoscopy; Personnel; Survey

Received: December 1, 2020 Revised: January 21, 2021

Accepted: February 19, 2021

Correspondence: Chang-Hwan Park

Department of Internal Medicine, Chonnam National University Medical School,

42 Jaebong-ro, Dong-gu, Gwangju 61469, Korea

Tel: +82-62-220-6296, Fax: +82-62-228-1330, E-mail: p1052ccy@jnu.ac.kr

ORCID: https://orcid.org/0000-0002-2995-8779

Correspondence: Byung Ik Jang

Department of Internal Medicine, Yeungnam University College of Medicine, 170

Hyeonchung-ro, Nam-gu, Daegu 42415, Korea

Tel: +82-53-620-3831, Fax: +82-53-654-8386, E-mail: jbi@med.yu.ac.kr

ORCID: https://orcid.org/0000-0002-3037-9272

*These authors contributed equally to this study.

cc This is an Open Access article distributed under the terms of the Creative Commons Attribution Non-Commercial License (http://creativecommons.org/ licenses/by-nc/3.0) which permits unrestricted non-commercial use, distribution, and reproduction in any medium, provided the original work is properly cited.

\section{INTRODUCTION}

Gastrointestinal endoscopy with a diagnostic or screening purpose is becoming increasingly utilized worldwide..$^{1-4}$ In addition, the indications for therapeutic endoscopic procedures are still expanding due to advancements in the equipment and techniques such as endoscopic resection of tumors, endoscopic retrograde cholangiopancreatography, and endoscopic ultrasonography-guided intervention. ${ }^{5-7}$ The majority of exams are performed under sedation to satisfy both the patient and endoscopist. Therefore, endoscopy units need to be properly prepared to ensure safety and effectiveness. Although several guidelines for endoscopic sedation have been proposed, the 
majority of the statements are based on experts' opinions due to the lack of relevant evidence. ${ }^{8-10}$ In this study, the results of a nationwide survey on the facilities, equipment, and personnel for endoscopic sedation from 50 qualified endoscopy units of teaching hospitals accredited by the Korean Society of Gastrointestinal Endoscopy (KSGE) are presented.

\section{MATERIALS AND METHODS}

First, a pilot survey was conducted using a questionnaire developed by the Quality management and Endoscopic sedation committee of KSGE among senior endoscopists and head nurses in charge of each of the 13 endoscopy units of board members of the committee via a website (https://ko.surveymonkey.com) between August $1^{\text {st }}$ and $30^{\text {th }}, 2018$. After the interim analysis, the updated questionnaire was generated and redistributed to 50 qualified endoscopy units of teaching hospitals accredited by the KSGE between October $15^{\text {th }}$ and November $15^{\text {th }}, 2018$ (Supplementary File). Data were summarized using descriptive statistics and presented as mean values with standard deviation (SD) or median values with ranges.

\section{RESULTS}

\section{Staff training and pre-procedural assessments}

The mean number (SD) of endoscopists affiliated with the Subspecialty Board of Gastrointestinal Endoscopy by the KSGE in each hospital was 10.2 (5.2) (Table 1). All endoscopy units had regulations regarding both initial and maintenance training for the endoscopists and nursing personnel, includ- ing registered nurses (RNs), nursing assistants, and assistants. All staff members from all of the enrolled endoscopic units had completed educational programs related to endoscopic sedation. They attended educational programs for propofol sedation endorsed by the Korean Medical Association (KMA) (8.0\%); seminars or workshops provided by the KSGE (46.0\%); and training sessions approved by the Korean Nurses Association and the Korean Society of Gastrointestinal Endoscopy Nurses and Associates (48.0\%), and their own educational programs (62.0\%).

A total of $41(82.0 \%)$ endoscopy units evaluated and kept records of the American Society of Anesthesiologist (ASA) Physical Status Classification System scores as part of the pre-procedural assessment (Table 2). Most of the units evaluated the ASA scores in more than $75 \%$ patients. A total of 34 (68.0\%) endoscopy units also included the Mallampati score that was assessed in more than $75 \%$ patients in $50 \%$ of the units and less than $25 \%$ patients in $42.8 \%$ of the units.

\section{Intra-procedure assessment}

\section{Working personnel and vital sign monitoring}

At least one member of the nursing personnel was always present in the examination room, even during diagnostic endoscopies, in all hospitals (Table 3). There was one nurse in 35 (70.0\%) endoscopy units and at least two nurses in 12 (24.0\%) units.

All endoscopy units had examination rooms equipped with oxygen supply and suction systems. Oxygen was supplied prior to administering sedatives in 32 (64.0\%) endoscopy units and was supplied in cases of hypoxia in all units. Forty (80\%) endoscopy units had electrocardiography (ECG), blood pres-

Table 1. Training of Working Personnel $(n=50)$

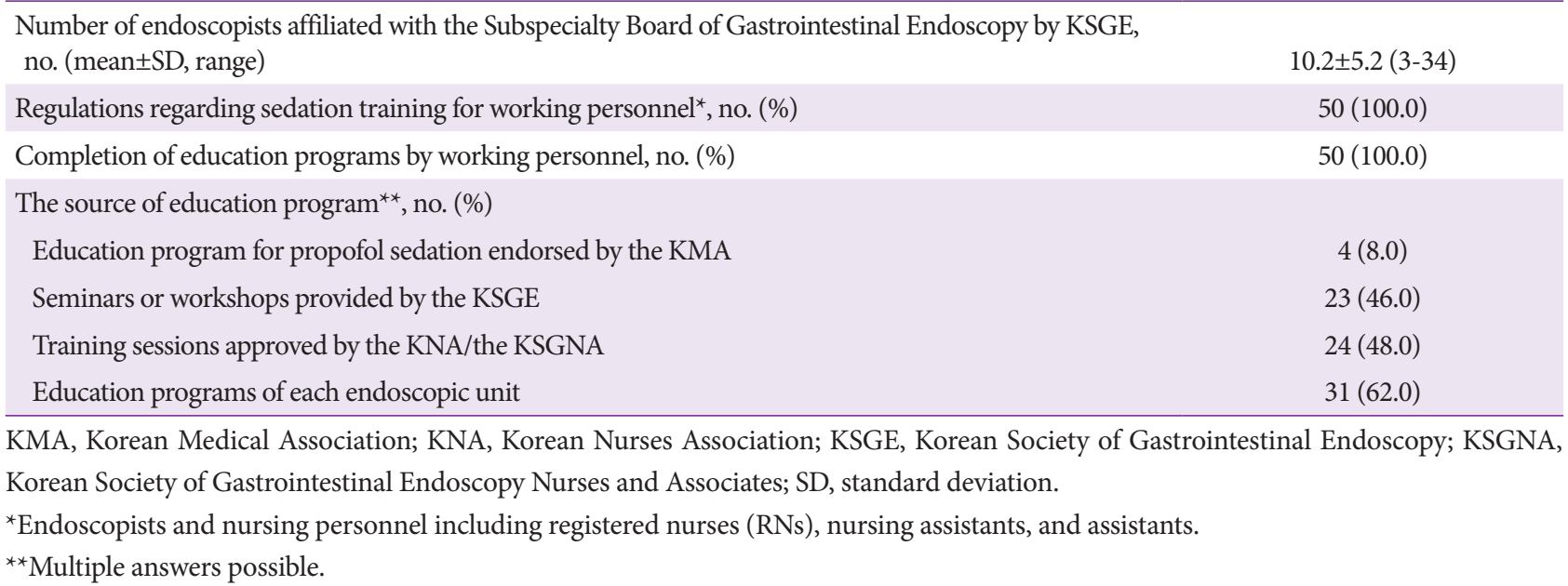


Table 2. Pre-Procedural Assessment $(n=50)$

\begin{tabular}{lc}
\hline ASA Physical Status Classification scores, no. (\%) & $41(82.0)$ \\
$>75 \%$ of patients & $37(91.3)$ \\
$50-75 \%$ of patients & $0(0)$ \\
$25-50 \%$ of patients & $0(0)$ \\
$<25 \%$ of patients & $4(8.7)$ \\
Mallampati score, no. $\%)$ & $34(68.0)$ \\
$>75 \%$ of patients & $18(52.9)$ \\
$50-75 \%$ of patients & $1(3.6)$ \\
$25-50 \%$ of patients & $1(3.6)$ \\
$<25 \%$ of patients & $14(41.1)$ \\
\hline
\end{tabular}

ASA, American Society of Anesthesiologists.

Table 3. Intra-Procedure Assessment $(n=50)$

Number of monitoring personnel present during an examination, no. (\%)

1 member of the nursing personnel

$35(70.0)$

2 or more members of the nursing personnel

$12(24.0)$

Another doctor

$3(6.0 \%)$

Equipment with oxygen supply and suction systems, no. (\%)

$50(100.0)$

Oxygen supply, no. (\%)

In case of hypoxia

$50(100.0)$

Routine supply before administration of sedatives

$32(64.0)$

Monitoring equipment ${ }^{\star}$ at each bed in the examination room, no. (\%)

$40(80.0)$

Regular measurement of vital signs

Oxygen saturation

$50(100.0)^{* *}$

Blood pressure

$50(100.0)$

$>75 \%$ of patients

$37(74.0)$

$50-75 \%$ of patients

$2(4.0)$

$25-50 \%$ of patients

$2(4.0)$

$<25 \%$ of patients

Electrocardiography

$50(100.0)$

$>75 \%$ of patients

$23(46.0)$

$50-75 \%$ of patients

$25-50 \%$ of patients

$3(6.0)$

$<25 \%$ of patients

Level of consciousness

$>75 \%$ of patients

$50-75 \%$ of patients

$25-50 \%$ of patients

$1(2.0)$

$<25 \%$ of patients

$3(6.0)$

*includes electrocardiography, blood pressure, and oxygen saturation.

${ }^{* *}$ continuous monitoring for every patient. 
sure (BP), and oxygen saturation (OS) monitoring equipment for each bed in the examination room. OS levels were monitored during all endoscopies. BP was measured regularly in $>3 / 4$ patients during examinations in 37 (74.0\%) endoscopy units, ECG monitoring was performed in $>3 / 4$ patients in 23 (46.0\%) units, and level of consciousness was assessed in $>3 / 4$ patients in $44(88.0 \%)$ endoscopy units.

\section{Drug administration practice and management of adverse events}

The type of sedatives, initial dose, and additional dosing intervals were decided by an endoscopist in 47 (94.0\%) endoscopy units (Table 4). The sedatives used were midazolam (36.0\%), propofol $(22.0 \%)$, and midazolam together with propofol (54.0\%). All endoscopy units had sedative antidotes, such as flumazenil and naloxone, available in the examination room. Sedative antidotes were used in cases of hypoxia in 39 (78.0\%) endoscopy units and for paradoxical responses in 34
(68.0\%) units. Patients with paradoxical responses were re-examined under non-sedation state after recovery through the use of an antidote in 48 (96.0\%) endoscopy units. Equipment for cardiopulmonary resuscitation were available in 49 (98.0\%) endoscopy units. Records of sedation endoscopy-related adverse events (AEs) were maintained in 37 (74.0\%) endoscopy units.

\section{Post-procedural assessment and discharge}

\section{Facility}

Each endoscopy unit was equipped with a separate recovery bay. The mean size (SD) of recovery bays was 67.8 (48.7) $\mathrm{m}^{2}$ (range, 6.5-240.0 $\mathrm{m}^{2}$ ). The mean number (SD) of beds in recovery bays was 13.8 (6.7) (range, 3-35). The number of endoscopy units with $<10$ patients per bed was 33 (66.0\%). Forty three (86.0\%) endoscopy units were equipped with oxygen supply, and 38 (76.0\%) had ECG/BP/OS monitoring equip-

Table 4. Drug Administration Practice and Management of Adverse Events $(n=50)$

\begin{tabular}{|c|c|}
\hline \multicolumn{2}{|c|}{ Decision of sedatives, initial dose, and additional dosing interval, no. (\%) } \\
\hline Endoscopist & $47(94.0)$ \\
\hline Another doctor & $1(2.0)$ \\
\hline Anesthesiologist & $1(2.0)$ \\
\hline Trained nurse & $1(2.0)$ \\
\hline \multicolumn{2}{|l|}{ Type of sedatives*, no. (\%) } \\
\hline Midazolam & $18(36.0)$ \\
\hline Propofol, single & $11(22.0)$ \\
\hline Propofol, balanced with midazolam & $27(54.0)$ \\
\hline Other & $1(2.0)$ \\
\hline Availability of antidotes in the examination room, no. (\%) & $50(100.0)$ \\
\hline \multicolumn{2}{|l|}{ Indication of antidotes*, no. (\%) } \\
\hline Hypoxia & $39(78.0)$ \\
\hline Paradoxical response & $34(68.0)$ \\
\hline Routine use & $5(10.0)$ \\
\hline Other & $1(2.0)$ \\
\hline \multicolumn{2}{|l|}{ Management of paradoxical response ${ }^{*}$ no. (\%) } \\
\hline Non-sedated exam with use of antidotes & $48(96.0)$ \\
\hline Additional dosing with another sedative & $39(78.0)$ \\
\hline Additional dosing with the same sedative & $5(10.0)$ \\
\hline Other & $2(4.0)$ \\
\hline Equipment for cardiopulmonary resuscitation, no. (\%) & $49(98.0)$ \\
\hline Keeping records of adverse events related to sedation, no. (\%) & $37(74.0)$ \\
\hline
\end{tabular}

${ }^{\star}$ Multiple answers possible 
Table 5. Post-Procedural Assessment and Discharge $(n=50)$

\begin{tabular}{lc}
\hline Size of recovery rooms, $\mathrm{m}^{2}$, mean $\pm \mathrm{SD}$ (range) & $67.8 \pm 48.7(6.5-240)$ \\
\hline Number of beds in recovery rooms, mean \pm SD (range) & $13.8 \pm 6.7(3-35)$ \\
\hline Number of beds in recovery rooms/number of patients, no. (\%) & $33(66.0)$ \\
$<1 / 10$ & $9(18)$ \\
$1 / 10-1 / 15$ & $4(8.0)$ \\
$1 / 15-1 / 30$ & $4(8.0)$ \\
$>1 / 30$ & $47(94.0)$ \\
Equipment with portable oxygen tanks for emergency, no. $(\%)$ & $47(94.0)$ \\
Specific assignment of nursing personnel for recovery rooms & $1.5 \pm 0.5(1-6)$ \\
\hline Number of nursing personnel, mean \pm SD (range) & $24(48.0)$ \\
Number of nursing personnel in recovery rooms/number of patients, no. $(\%)$ & $12(24.0)$ \\
$<1 / 10$ & $10(20.0)$ \\
$1 / 10-1 / 15$ & $4(8.0 \%)$ \\
$1 / 15-1 / 30$ & $50(100.0)$ \\
$>1 / 30$ & $50(100.0)$ \\
\hline Fulfilling the discharge criteria & \\
\hline Recommendation for an outpatient to be accompanied by a guardian & \\
\hline
\end{tabular}

SD, standard deviation.

ment for each bed in the recovery bays. In addition, 47 (94.0\%) units were equipped with portable oxygen tanks, which could be readily used when necessary.

\section{Working personnel}

There were 47 (94.0\%) endoscopy units with nursing personnel assigned solely to recovery bays. The mean number (SD) of members of the nursing personnel was 1.5 (0.5) (range, 1-6). In 24 (48.0\%) endoscopy units, less than 10 patients were cared for by a single member of the nursing personnel (Table $5)$.

\section{Discharge criteria}

All endoscopy units fulfilled the discharge criteria and put forward a recommendation that every outpatient should be accompanied by a caretaker when discharged (Table 5).

\section{DISCUSSION}

The characteristics of a real-world clinical practice of sedative endoscopy regarding the staff, facilities, and performance in 50 qualified endoscopy units of teaching hospitals accredited by the KSGE in South Korea were evaluated in the present study. All endoscopic units conformed to the previous version of the Accreditation of Qualified Endoscopy Unit (AQEU) program provided by the KSGE. One of the prerequisites for training hospitals for endoscopic performance is to achieve the AQEU program provided by the KSGE in South Korea. The KSGE introduced the AQEU program to enhance the quality of endoscopy units through systematic quality management in 2012. ${ }^{11}$ In this program, crucial factors required to deliver the best endoscopy practice are as follows: (I) staff credentialing; (II) compliance with the guidelines for safety, endoscope disinfection, and endoscopic sedation according to the policy of each institution as recommended by the KSGE; (III) assessment of the standardized procedures to meet performance criteria; and (IV) continuous quality improvement activities. To provide evidence for updating the AQEU program in 2019, a nationwide survey was conducted, and the items related to endoscopic sedation are described herein.

Sedation is defined as a depressed level of consciousness induced by drug administration. When gastrointestinal endoscopy is performed, sedation is frequently used, benefiting both the patient and the endoscopist. In patients, anxiety and discomfort can be relieved by sedation. In addition, a lack of memory of the procedure may be anticipated. For an endoscopist, the quality of the examination is improved in the absence 
of unintended patient's movements. The level of sedation is a continuum ranging from minimal sedation (anxiolysis) to general anesthesia, which is defined by a patient's degree of spontaneous ventilation, maintenance of cardiovascular function, and response to verbal and tactile stimuli. The targeted level of sedation may differ depending on the patient's condition and the length or complexity of the procedure. Usually, moderate sedation is preferred. Deep sedation, however, may be achieved with or without intention, in which case the risk of serious AEs, such as cardiopulmonary compromise, increases. ${ }^{12}$ Pre-procedural evaluation to assess the risk stratification is required for all patients undergoing endoscopic sedation. ${ }^{13}$ A previous nationwide survey in South Korea showed that $56.6 \%$ of respondents in the non-academic setting and $74.8 \%$ of respondents from academic endoscopy units used ASA scores. In our study, $82 \%$ of endoscopy units maintained the ASA score as a patient assessment method prior to sedation, which was attributable to a change in perception regarding sedative endoscopy, especially regarding safety issues. We included the Mallampati score as a patient assessment method prior to sedation in the survey. In this study, only $68 \%$ of the units recorded the Mallampati score. The modified Mallampati classification may predict the ease of endotracheal intubation, and an increased Mallampati score has been shown to be a predictor of the need for anesthesia-directed airway manipulation..$^{15}$ As the KSGE has recently released an updated version of the AQEU program including Mallampati scoring for the assessment of airway anatomy, its use is expected to become more popular.

Both patient and procedural factors should be considered when determining the staff requirements for the endoscopy procedure. ${ }^{16}$ Patient factors were determined from the underlying comorbid diseases and physical examination and were reflected in the ASA scores. Procedural factors include the anticipated length of the procedure and whether a procedure is intended to be diagnostic or therapeutic. Complex interventional procedures may require additional members of the personnel for their efficiency.

The Standards of Practice Committee of the American Society for Gastrointestinal Endoscopy (ASGE) recommended that for endoscopies with moderate sedation, one RN may administer sedation under the supervision of a physician and assist with the technical portion of the endoscopic procedure, provided that these tasks are interruptible. ${ }^{17}$ In addition, it was recommended that complex endoscopic procedures be staffed with a second endoscopy assistant, and if a RN administers deep sedation under the supervision of a physician, then a second endoscopy assistant should be included. Unfortunately, these recommendations are not fully supported by the real-world data. To the best of our knowledge, the only reference regarding the staff choice of endoscopy units is a questionnaire survey from 63 ambulatory endoscopy centers, where sedation was performed by an anesthesia specialist in Texas, United States. ${ }^{18}$ According to their results, 49 (78\%) centers involved a single personnel member per endoscopy room, and additional personnel members were present performing tasks not directly related to patient care in $14 / 63$ units (22\%). The staffing model was different from the one in our study in that it was restricted to ambulatory centers performing upper endoscopies and colonoscopies. Our data reflect the overall situation in real-world practice, including ambulatory and hospital-based endoscopy units. In our study, 70\% of the enrolled endoscopy units involved one member of the nursing personnel, and 24\% involved at least two members of the nursing personnel during sedation diagnostic endoscopies. In most endoscopic units in South Korea, endoscopist-directed moderate or deep sedation is performed for routine or advanced procedures. Therefore, one nurse attending almost all diagnostic procedures should perform multiple tasks, such as patient monitoring, technical activities, and recording nursing documents. However, in case of advanced procedures, additional members of the nursing personnel dedicated to patient monitoring are necessary. Therefore, it is crucial to define, educate, and promote the role of additional members of the nursing personnel during advanced endoscopic procedures with endoscopist-directed moderate or deep sedation for patients' safety and effectiveness of the procedures.

For sedation-related equipment, the ASGE recommends that oxygen supply; suction for the mouth; and electronic equipment that can monitor and display pulse, BP, OS, and continuous ECG assessment should be available in the procedure room. ${ }^{9}$ In addition, the frequency of monitoring activity depends on the procedural and patient factors. The updated program for the AQEU by the KSGE recommends that each bed in the examination rooms must be equipped with an oxygen supply and a patient monitoring system for checking $\mathrm{BP}$, heart rate, and OS. ${ }^{7}$ At a minimum, monitoring should be performed before the procedure, after administration of sedatives, at regular intervals during the procedure, during initial recovery, and just before discharge. In our study, all endoscopy units had examination rooms equipped with oxygen supply, suction, and monitoring systems. Clinical guidelines for sedative endoscopy from the Spanish Society of Digestive Endoscopy recommend preoxygenation for 5 min before sedative endoscopy, as it reduces the incidence of arterial desaturation. ${ }^{19}$ In this study, 32 (64\%) centers supplied oxygen before the administration of sedatives. It is necessary to define the indication of preoxygenation to prevent hypoxemia in patients at high risk for sedative endoscopy and to highlight the necessity of preoxygenation. 
In the aforementioned nationwide survey in South Korea, propofol-based sedation was the preferred method due to the highest satisfaction of both patients and endoscopists. ${ }^{14}$ It was the most preferred method in the majority of endoscopy units in 2019. The reasons for the preference of propofol were that propofol sedation during the endoscopic procedure provides better patient satisfaction and endoscopist's satisfaction without an increase in AEs. Moreover, propofol for procedural sedation can be used by non-anesthesiologists in South Korea. Meanwhile, in 2016, the KMA stated that an educational program is mandatory for every doctor and member of the nursing personnel involved in propofol-based sedation. ${ }^{20}$ However, working personnel from four $(8.0 \%)$ centers responded that they completed the education program for propofol sedation endorsed by the KMA, in which a more active participation is required.

The ASGE recommends that recovery bays provide privacy and sufficient space for monitoring care, and that unit facilities provide recovery appropriate to the level of sedation utilized. ${ }^{16}$ Regarding the post-procedure staff care, at least one $\mathrm{RN}$ is required to monitor patients who have received sedation until the patient is stabilized and to assess for AEs related to the endoscopic procedures, although the ratio of RNs to patients in the post-procedure setting varies depending on the acuity of the patients. In the present study, $94 \%$ of the responses showed that at least one member of the nursing personnel was assigned to recovery bays for post-procedural care. In addition, while $88 \%$ of responders regarded the ideal ratio of nursing personnel to patients as 1:10 or lesser, less than half of the endoscopy units met this expectation. There have been no guidelines concerning this issue to date. Assessment studies to balance the ratio of nursing personnel to patients for safety and effectiveness are anticipated.

This study has several limitations. First, only responses from the endoscopic units of teaching hospitals were included. Therefore, our data do not encompass the entire clinical situation in South Korea. Second, a recall bias may be an issue, similar to self-reported surveys. Third, this study did not include the rate of sedation-related AEs, for which another study was designed by the KSGE. Fourth, our data did not segregate the data by types of endoscopic procedures.

In conclusion, this study presented the details of endoscopic sedation in real-world practice via a survey on 50 qualified endoscopy units of teaching hospitals in South Korea. Further studies are needed to determine the prevalence and outcomes of sedation-related AEs, especially by the types of endoscopic procedures and the effects of the educational programs on endoscopic sedation.
Conflicts of Interest

The authors have no potential conflicts of interest.

Funding

None.

Author Contributions

Conceptualization: The Committees of Quality Management and Conscious Sedation of Korean Society of Gastrointestinal Endoscopy (KSGE)

Data curation: Jun Kyu Lee, Jung-Wook Kim, Tae Hee Lee, Jae-Yong Jang, Byung-Wook Kim

Formal analysis: JKL, Seon-Young Park

Investigation: KSGE

Project administration: Byung Ik Jang, Chang-Hwan Park

Supervision: BIJ, CHP

Validation: KSGE

Writing-original draft: SYP, JKL

Writing-review\&editing: SYP, JKL, CHP

\section{ORCID}

Seon-Young Park: Jun Kyu Lee:

Jung-Wook Kim:

Tae Hee Lee:

Chang-Hwan Park:

Byung-Wook Kim:

Byung Ik Jang:
Jae-Yong Jang:

\begin{abstract}
https://orcid.org/0000-0002-0962-5977 https://orcid.org/0000-0002-2694-3598 https://orcid.org/0000-0002-5383-7934 https://orcid.org/0000-0003-3049-8252 https://orcid.org/0000-0002-2995-8779 https://orcid.org/0000-0002-7930-1468 https://orcid.org/0000-0002-2290-4954 https://orcid.org/0000-0002-3037-9272
\end{abstract}

\section{REFERECES}

1. Cho YK. How to Improve the quality of screening endoscopy in Korea: national endoscopy quality improvement program. Clin Endosc 2016;49:312-317.

2. Chen R, Liu Y, Song G, et al. Effectiveness of one-time endoscopic screening programme in prevention of upper gastrointestinal cancer in China: a multicentre population-based cohort study. Gut 2021;70:251260.

3. Rex DK, Boland CR, Dominitz JA, et al. Colorectal cancer screening: recommendations for physicians and patients from the U.S. Multi-Society Task Force on colorectal cancer. Am J Gastroenterol 2017;112:10161030.

4. Săftoiu A, Hassan C, Areia M, et al. Role of gastrointestinal endoscopy in the screening of digestive tract cancers in Europe: European Society of Gastrointestinal Endoscopy (ESGE) Position Statement. Endoscopy 2020;52:293-304.

5. ASGE Technology Committee, Lo SK, Fujii-Lau LL, et al. The use of carbon dioxide in gastrointestinal endoscopy. Gastrointest Endosc 2016;83:857-865

6. Mulder CJ, Tan AC, Huibregeste K. Guidelines for designing an endoscopy unit: report of the Dutch Society of Gastroenterologists. Endoscopy 1997;29:I-VI

7. Lee TH, Yoon JY, Paik CN, Choi HS, Jang J-Y. Updates on the facilities, procedures, and performance of the accredited endoscopy unit. Clin Endosc 2019;52:431-442.

8. Dumonceau J-M, Riphaus A, Schreiber F, et al. Non-anesthesiologist administration of propofol for gastrointestinal endoscopy: European Society of Gastrointestinal Endoscopy, European Society of Gastroenterology and Endoscopy Nurses and Associates guideline--updated June 2015. Endoscopy 2015;47:1175-1189. 
9. ASGE Standards of Practice Committee, Early DS, Lightdale JR, et al. Guidelines for sedation and anesthesia in GI endoscopy. Gastrointest Endosc 2018;87:327-337.

10. Gotoda T, Akamatsu T, Abe S, et al. Guidelines for sedation in gastroenterological endoscopy (second edition). Dig Endosc 2021;33:21-53.

11. Kim J-W, Cho YK, Kim J-O, Jang J-Y. Accredited endoscopy unit program of Korea: overview and qualification. Clin Endosc 2019;52:426430.

12. Lee JK, Lee YJ, Cho JH, et al. Updates on the sedation for gastrointestinal endoscopy. Clin Endosc 2019;52:451-457.

13. ASGE Standards of Practice Committee, Early DS, Lightdale JR, et al. Guidelines for sedation and anesthesia in GI endoscopy. Gastrointest Endosc 2018;87:327-337.

14. Lee CK, Dong SH, Kim ES, et al. Room for quality improvement in endoscopist-directed sedation: results from the first nationwide survey in Korea. Gut Liver 2016;10:83-94.

15. American Association for Study of Liver Diseases, American College of Gastroenterology, American Gastroenterological Association Institute, et al. Multisociety sedation curriculum for gastrointestinal endoscopy. Gastrointest Endosc 2012;76:e1-e25.

16. ASGE Ensuring Safety in the Gastrointestinal Endoscopy Unit Task Force, Calderwood AH, Chapman FJ, et al. Guidelines for safety in the gastrointestinal endoscopy unit. Gastrointest Endosc 2014;79:363-372.

17. ASGE Standards of Practice Committee, Jain R, Ikenberry SO, et al. Minimum staffing requirements for the performance of GI endoscopy. Gastrointest Endosc 2010;72:469-470.

18. Agrawal D, Jain R. Staffing at ambulatory endoscopy centers in the United States: practice, trends, and rationale. Gastroenterol Res Pract 2018;2018:9463670.

19. Igea F, Casellas JA, González-Huix F, et al. Sedation for gastrointestinal endoscopy. Endoscopy 2014;46:720-731.

20. Kang H, Kim DK, Choi Y-S, Yoo Y-C, Chung HS. Practice guidelines for propofol sedation by non-anesthesiologists: the Korean Society of Anesthesiologists Task Force recommendations on propofol sedation. Korean J Anesthesiol 2016;69:545-554. 